\title{
Critical phosphate salt concentrations leading to altered micellar casein structures and functional intermediates
}

\author{
Y. Saricay, C. A. Hettiarachchi, M. D. Culler, and F. M. Harte* \\ Department of Food Science, Pennsylvania State University, University Park 16802
}

\begin{abstract}
We investigated the effect of different phosphate salts on the structural integrity of micellar casein (MC) at $\mathrm{pH}$ 7.0. With the increase of salt concentration, a reduction in turbidity was observed for the MC solutions, and it was modeled using an exponential decay function. The inflection point of the model was defined as the first critical salt concentration $\left(\mathrm{C}^{*}\right)$, and it is suggested that the salt concentration initiates the disintegration of MC. For linear polyphosphates, $\mathrm{C}^{*}$ decreased with the number of phosphate groups. Apparent viscosity $\left(\eta_{\text {app }}\right)$ of MC solutions increased with the increase of salt concentration, and they recorded a peak while the turbidity decreased to a minimum. The salt concentration that resulted in the highest $\eta_{\text {app }}$ was identified as the second critical salt concentration $\left(\mathrm{C}^{* *}\right)$. It is hypothesized that the interactions among protein species present in the mixtures are at an optimum state at $\mathrm{C}^{* *}$. Both $\mathrm{C}^{*}$ and $\mathrm{C}^{* *}$ were found to be dependent on the MC concentration. The work presented herein supports an understanding of the concentration effect of phosphate salts on MC for structuring dairy products. Key words: micellar casein, phosphate salt, rheology, turbidity
\end{abstract}

\section{INTRODUCTION}

Caseins, the predominant proteins found in bovine milk $(\sim 80 \%)$ are phosphoproteins (Kumosinski and Farrell, 1991; Kawasaki and Weiss, 2003) that serve as the primary source of calcium, phosphate, and AA to the neonate. The individual caseins $\left(\alpha_{\mathrm{S}^{-}} \mathrm{CN}, \alpha_{\mathrm{S}^{-}}\right.$ $\mathrm{CN}, \beta-\mathrm{CN}$, and $\kappa-\mathrm{CN}$ ) interact with multiple colloidal calcium phosphate (CCP) nanoclusters, resulting in highly hydrated supramolecular structures known as casein micelles, with an average diameter of $\sim 150$ nm (Dalgleish, 2011; Trejo et al., 2011; de Kruif et al., 2012; Holt et al., 2013). Hydrophobic interactions

Received September 24, 2018.

Accepted April 23, 2019.

*Corresponding author: fede@psu.edu among the caseins also contribute to the stability of the casein micelles (Horne, 1998). The higher negative charge density of the glycomacropeptide of $\kappa$-CN (residues 106-169), which occupy the surface of the casein micelles, prevents the aggregation of adjacent micelles at physiological $\mathrm{pH}$ values (Creamer et al., 1998).

The stability of casein micelles strongly depends on extrinsic conditions, including $\mathrm{pH}$, temperature, ionic strength, and type of ions presented in the medium (Broyard and Gaucheron, 2015), and this character is used to obtain desired textural attributes in dairy foods. A prime example is the use of emulsifying salts to tune smoothness, homogeneity, and melting properties of processed cheese (Kapoor and Metzger, 2008; Chavhan et al., 2015; Hougaard et al., 2015). These salts can chelate calcium ions from CCP nanoclusters, and thereby destabilize and disintegrate casein micelles into smaller assemblies of caseins (Panouillé et al., 2005; Pitkowski et al., 2008). These casein monomers are reported to exhibit an enhanced absorptivity at fatwater interface stabilizing cheese emulsions (Hougaard et al., 2015). Moreover, casein monomers acquire a higher hydrodynamic volume in comparison to intact micelles, increasing the apparent viscosity of the system (de Kort et al., 2011). In addition to the disintegration of micelles, certain emulsifying salts can trigger interactions among casein monomers, forming a network that leads to a hydrogel (Mizuno and Lucey, 2007).

Three types of emulsifying salts are used in processed cheese, namely, phosphate, citrate, and tartrate salts. Recently, we reported 4 trends that can be observed in the turbidity of diluted milk with increasing concentrations of these salts, which are (1) no appreciable decrease in turbidity, (2) continuous decrease in turbidity, (3) turbidity decreases and reaches a constant phase, and (4) turbidity decreases, but then increases at higher salt concentrations (Culler et al., 2017). Among these salts, phosphates are commonly used and can be categorized into 2 sub-groups: monomeric phosphates, also called orthophosphates (single phosphate group) and polymeric phosphates, or polyphosphates (multiple phosphate groups; Lucey et al., 2011). Polyphosphates can be further classified as linear (short- and long-chain 
polyphosphates), ring-forming (metaphosphates), and cross-linked (ultraphosphates).

Micellar casein (MC) powders are typically produced by spray drying of skim milk that had been subjected to microfiltration and diafiltration $(0.1-0.2 \mu \mathrm{m})$ for the removal of lactose, salts, and whey proteins (Schokker et al., 2011). Native structure of casein micelles are much more preserved in these powders compared with caseinates produced by acid precipitation and neutralization (Carr and Golding, 2016), and these powders have a higher potential to be used in manufacturing of cheese as the use of MC-enriched milk in cheese making has led to faster coagulation, higher curd rigidity, and increased cheese yield (Caron et al., 1997; St-Gelais et al., 1998).

Use of phosphate salts in processed cheese and the possibility of inclusion of $\mathrm{MC}$ as an ingredient in liquid formulations require investigating the effect of these salts on micellar structures and rheological properties of MC-enriched milks. This study was aimed at determining the effect of phosphate salt type, number of phosphate groups, and concentration of the salt on the viscoelastic properties and turbidity of $\mathrm{MC}$ solutions, and thereby to predict the structural changes associated with micellar structures.

\section{MATERIALS AND METHODS}

\section{Materials}

An additive-free, commercial MC powder containing $\sim 87 \%$ protein and $\sim 7 \%$ lactose was used for this study (Naked Nutrition, Coral Gables, FL). Mineral content of the powder was $\sim 36 \mathrm{mg}$ per $\mathrm{g}$ of powder with $\sim 20 \mathrm{mg}$ being calcium. According to the information provided by the manufacturer, the MC was produced from skim milk following an acid-free, bleach-free cold process. Sodium phosphate monobasic (CAS 7558-80-7, phosphates $=1$, MSP), sodium pyrophosphate tetrabasic (CAS 7722-88-5, phosphates $=2$, TSPP), sodium polyphosphate (CAS 68915-31-1, molecular weight $1,733 \mathrm{~g} \cdot \mathrm{mol}^{-1}$, phosphates $=17$, linear, SPP), and HEPES buffer were obtained from Sigma-Aldrich (St. Louis, MO). Sodium tripolyphosphate (CAS 7758-29-4, phosphates $=3$, linear, STPP), sodium trimetaphosphate (CAS 7785-84-4, phosphates = 3, ring, STMP), and sodium hexametaphosphate (CAS 10124-56-8, phosphates $=6$, ring, SHMP) were purchased from Alfa Aesar (Ward Hill, MA). Water with a resistivity of $\sim 18.2 \mathrm{M} \Omega \cdot \mathrm{cm}$ was used for the preparation of solutions. $\mathrm{pH}$ determinations were performed at room temperature $\left(20 \pm 2^{\circ} \mathrm{C}\right)$ using an Ion 700 bench-top $\mathrm{pH}$ meter (Oakton, Vernon Hills, IL) that was calibrated before measurements. The $\mathrm{HCl}$ and $\mathrm{NaOH}$ (concentrated and diluted solutions as required) were used for $\mathrm{pH}$ adjustments.

\section{Characterization of MC}

A solution of $\mathrm{MC}(0.25 \% \mathrm{wt} / \mathrm{vol})$ was prepared using $10 \mathrm{~m} M$ HEPES buffer (pH 7.0). Sodium dodecyl sulfate PAGE was performed on an aliquot obtained from the above solution under reducing conditions (Laemmli, 1970). Casein to whey protein ratio in MC was determined by assessing the intensity of corresponding bands using ImageJ (Schneider et al., 2012). Hydrodynamic diameter of casein micelles (or micellar-like structures) present in the MC solution was determined using a dynamic light scattering device equipped with a 632.8 $\mathrm{nm}$ red laser and a back-scattering detector placed at an angle of $173^{\circ}$ (Nano-ZS, Malvern Instruments Ltd., Worcestershire, UK). A refractive index of 1.570 was used for the calculation of Z-average diameter of the particles (Ambrose Griffin and Griffin, 1985).

\section{Preparation of MC and Salt Solutions}

The MC stock solutions (10 and 12\% wt/vol) were made by dispersing the desired amount of MC powder in $10 \mathrm{~m} M$ HEPES buffer $(200 \mathrm{~mL})$ under continuous stirring for $30 \mathrm{~min}$ at $50^{\circ} \mathrm{C}$. Next, the $\mathrm{pH}$ of the $\mathrm{MC}$ stock solutions was adjusted to 7.0 and stored overnight in a refrigerator $\left(5 \pm 1^{\circ} \mathrm{C}\right)$. Stock solutions of phosphate salts $(200$ and $250 \mathrm{mM}$ ) were prepared by dissolving the appropriate amount of each salt in $10 \mathrm{~m} M$ HEPES buffer $(50 \mathrm{~mL})$. Solutions were stirred vigorously at $50^{\circ} \mathrm{C}$ until the added salt was entirely dissolved in the buffer. Next, the $\mathrm{pH}$ of the phosphate salt stock solutions was adjusted to 7.0, and a series of dilutions was prepared from each stock solution $(0-200 \mathrm{~m} M$ and $0-250 \mathrm{mM})$ using $10 \mathrm{~m} M$ HEPES buffer at $\mathrm{pH}$ 7.0. These salt solutions were stored overnight in the refrigerator.

\section{Preparation of MC-Salt Mixtures}

The MC-salt mixtures were prepared by mixing MC stock solutions with salt solutions at 1:1 (10\% wt/vol MC stock solution with $0,0.2,1,2,5,10,20,30,50$, 100 , and $200 \mathrm{mM}$ salt solutions) or $4: 1$ ratio (12\% wt/ vol MC stock solution with $0.5,2.5,5,12.5,25,50,75$, 125 , and $250 \mathrm{mM}$ salt solutions) resulting in mixtures with a MC concentration of either 5 or $9.6 \% \mathrm{wt} / \mathrm{vol}$ with varying phosphate salts concentrations $(0-100 \mathrm{mM})$. Mixtures were vortexed for $10 \mathrm{~s}$ and kept overnight in the refrigerator $\left(\sim 5^{\circ} \mathrm{C}\right)$ before any evaluation. All the evaluations were conducted at $\sim 5^{\circ} \mathrm{C}$ to determine the 
effect of phosphate salts on the structural stability of $\mathrm{MC}$ and the functional properties of MC-salt mixtures under storage conditions.

\section{Turbidity Measurements}

Turbidity of MC-salt mixtures was measured as the absorbance at $400 \mathrm{~nm}$ using a ND-1000 spectrophotometer (NanoDrop, Wilmington, DE), without dilution. An aliquot $(2 \mu \mathrm{L})$ pipetted from a mixture was placed on the lower measurement pedestal, and the upper measurement pedestal was lowered so as to make contact with the sample. The absorbance was recorded on an automatically drawn sample column with a path length of $1 \mathrm{~mm}$. Mixtures were kept at $5 \pm 1^{\circ} \mathrm{C}$ until the moment of measurement. The HEPES buffer $(10 \mathrm{~m} M$, $\mathrm{pH}$ 7.0) was used as the blank.

For a given phosphate salt, turbidity (absorbance) values recorded at different salt concentrations were modeled with an exponential decay function (Culler et al., 2017):

$$
y=\left(A+A_{\text {res }}\right) e^{-C / C^{*}}+A_{\text {res }},
$$

where $y$ is the estimated absorbance (au), $A$ is the difference between the absorbance values measured at zero salt concentration and the highest salt concentration (au), $A_{\text {res }}$ is absorbance at the highest salt concentration (residual absorbance; au), $C$ is the salt concentration of the sample $(\mathrm{m} M)$, and $C^{*}$ is the salt concentration at the inflection point of the curve $(\mathrm{m} M)$.

\section{Rheology Measurements}

Dynamic viscoelastic studies were performed on a Discovery HR-3 rheometer (TA Instruments, New Castle, DE). Flow curves for 5 and $9.6 \%$ wt/vol MC-salt mixtures were obtained using a double-wall concentric cylinder geometry (inside cup diameter $=40.02 \mathrm{~mm}$, inside bob diameter $=40.77 \mathrm{~mm}$, outside cup diameter $=44.82 \mathrm{~mm}$, outside bob diameter $=43.88 \mathrm{~mm}$, inner cylinder height $=60.02 \mathrm{~mm}$, immersed height $=58.02$ $\mathrm{mm}$, operating gap $=2000 \mu \mathrm{m})$ and a cone-plate geometry (cone diameter $=60 \mathrm{~mm}$, cone angle $=0.995^{\circ}$, truncation gap $=30 \mu \mathrm{m})$, respectively, for the shear rate $(\gamma)$ range of 0.01 to $100 \mathrm{~s}^{-1}$ at $5^{\circ} \mathrm{C}$. Apparent viscosity versus shear rate curves were derived from the flow curves, and consistency coefficient and flow index of MC-salt mixtures were determined for the power law region of the viscosity curves by applying Equation [2]:

$$
\eta_{\text {app }}=K \gamma^{\prime n-1},
$$

where $\eta_{\text {app }}$ is the apparent viscosity $(\mathrm{Pa} \cdot \mathrm{s}), K$ is the consistency coefficient $\left(\mathrm{Pa} \cdot \mathrm{s}^{\mathrm{n}}\right), \gamma^{\prime}$ is the shear rate $\left(\mathrm{s}^{-1}\right)$, and $n$ is the flow index.

In addition, storage, loss, and complex moduli $\left(\mathbf{G}^{\prime}\right.$, $\mathbf{G}^{\prime \prime}$, and $\mathbf{G}^{*}$, respectively; $\mathrm{Pa}$ ) of $9.6 \% \mathrm{wt} / \mathrm{vol} \mathrm{MC}$-salt mixtures were determined using the cone-plate geometry at $5{ }^{\circ} \mathrm{C}$ applying an oscillation frequency of $1 \mathrm{~Hz}$ with $1 \%$ strain. The gelled MC-salt mixtures (10 and $15 \mathrm{~m} M$ TSPP and $5 \mathrm{~m} M$ SHMP) were stirred into a homogeneous solution before loading them into the geometry.

\section{Cryo-Electron Microscopy}

Selected MC-salt mixtures (with a $5 \%$ wt/vol MC) were subjected to cryo-electron microscopy (cryoEM). Each mixture at $\sim 5^{\circ} \mathrm{C}$ was diluted 20 -fold with $10 \mathrm{~m} M$ HEPES buffer ( $\mathrm{pH}$ 7.0) containing the same concentration of salt as in the mixture. An aliquot (3 $\mu \mathrm{L}$ ) obtained from the diluted mixture was deposited onto a glow-discharged holey carbon film supported on a 200-mesh copper grid (Ted Pella, Redding, CA) held in place by a Mark-IV Vitrobot unit (FEI, Hillsboro, OR) for automated cryo-preparation. The grid was then blotted for $2.5 \mathrm{~s}$ and vitrified by plunging into liquid ethane. Next the grid was transferred under liquid nitrogen on to a single-tilt cryo-holder (Gatan, Pleasanton, CA) and observed under low dose using a FEI Tecnai 12 BioTwin electron microscope operating at $120 \mathrm{kV}$. Images were obtained using a Gatan Orius SC 1000 CCD camera (Gatan Inc., Pleasanton, CA).

\section{RESULTS AND DISCUSSION}

\section{Characteristics of MC}

Casein to whey protein ratio of MC powder used for this study was estimated to be 86:14 based on SDSPAGE band intensities (Supplemental Figure S1; https: //doi.org/10.3168/jds.2018-15746). Typical casein to whey protein ratio for MC concentrates is reported to be 92:8 (Carr and Golding, 2016), thus the powder used for this study had a relatively higher whey protein content. A unimodal particle size distribution was observed for the casein micelles (or micellar-like structures) present in MC solution (Supplemental Figure S2; https://doi.org/10.3168/jds.2018-15746) with a Z-average diameter of $205 \pm 10 \mathrm{~nm}$ and a polydispersity index of $0.24 \pm 0.07$. However, it should be noted that the determined Z-average diameter could be an underestimate because the multiplication of the scattering vector $(\mathrm{q})$ from the hydrodynamic radius $\left(\mathrm{R}_{\mathrm{h}}\right)$ of the particle results in a value $>1$. 


\section{Effect of Salt Type and Salt Concentration on Turbidity and Viscosity}

Figure 1 illustrates turbidity and apparent viscosity, $\eta_{\text {app }}\left(\gamma^{\prime}=100 \mathrm{~s}^{-1}\right)$ of $5 \% \mathrm{wt} /$ vol MC-salt mixtures at different salt concentrations. All phosphate salts led to an exponential reduction in turbidity of MC solutions with the increase of salt concentration as modeled by Equation [1]. The reduction of turbidity was attributed to the disintegration of MC. The first critical salt concentration $\left(\mathbf{C}^{*}\right)$ obtained from the model was identified as the first critical salt concentration and the $\mathrm{C}^{*}$ values of different phosphate salts are presented in Table 1. The $\mathrm{C}^{*}$ decreased with the increase of number of phosphate groups in the salt (Table 1), suggesting that salts with a higher number of phosphate groups can induce similar structural changes in MC at lower concentrations. However, STMP did not follow this trend. a)

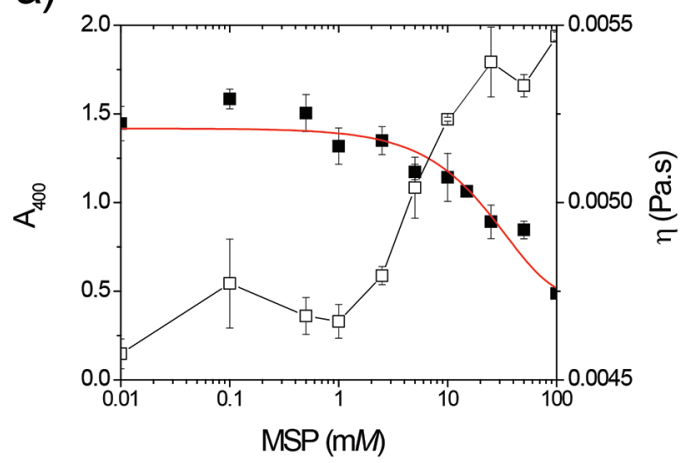

c)

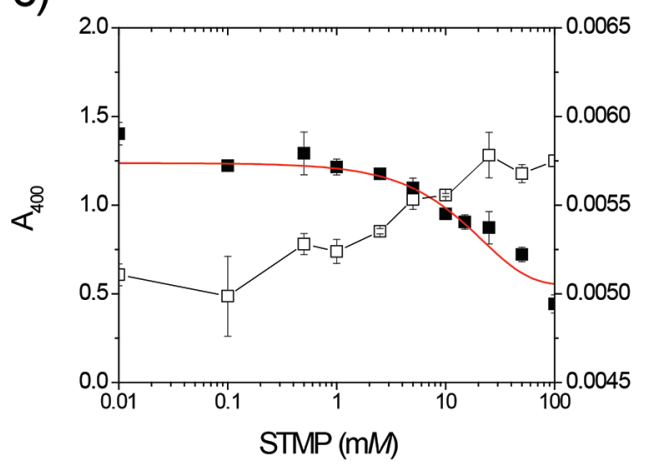

e)

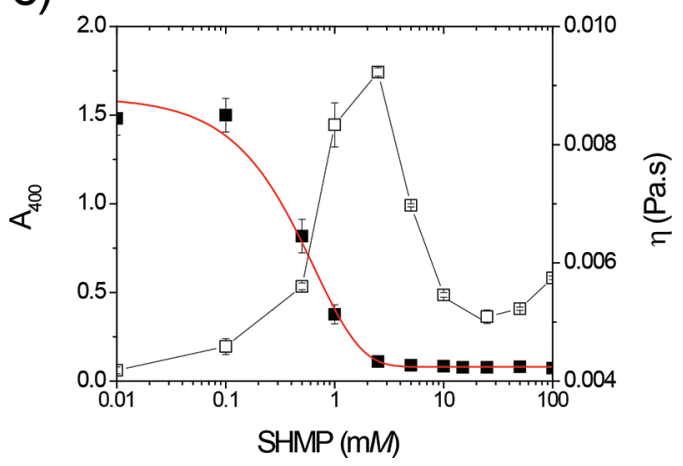

b)

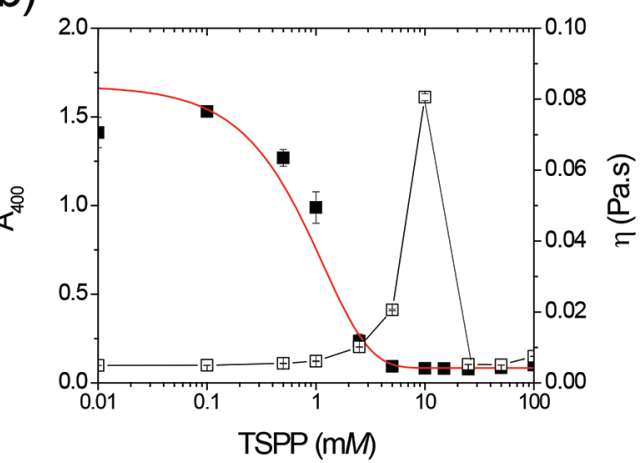

d)

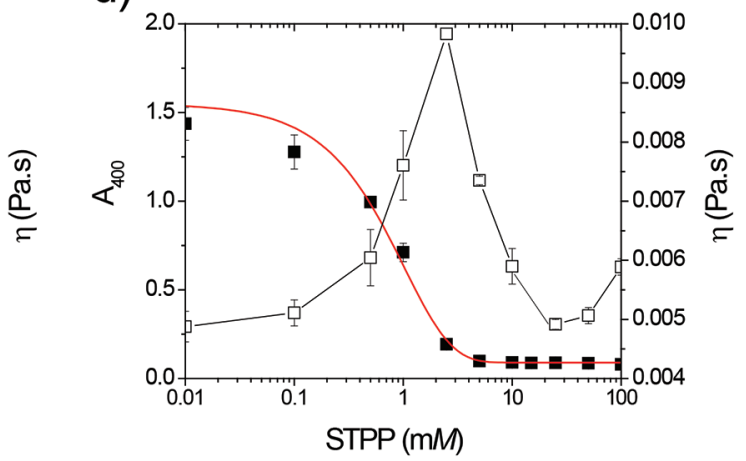

f)

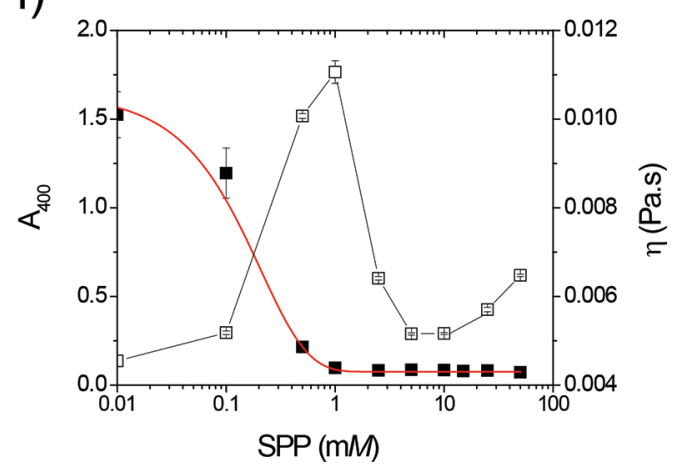

Figure 1. Turbidity (closed symbols) and apparent viscosity ( $\eta_{\text {app }}$; open symbols) of $5 \% \mathrm{wt} /$ vol micellar casein (MC)-salt mixtures with varying concentrations of different phosphate salts at $5^{\circ} \mathrm{C}$. (a) Sodium phosphate monobasic (MSP), (b) sodium pyrophosphate tetrabasic (TSPP), (c) sodium trimetaphosphate (STMP), (d) sodium tripolyphosphate (STPP), (e) sodium hexametaphosphate (SHMP), and (f) sodium polyphosphate (SPP). The MC-salt mixtures were prepared using $10 \mathrm{~m} M$ HEPES buffer $(\mathrm{pH}$ 7.0). The red curve shows the fitting of the exponential model (Equation [1]) to turbidity data. $\mathrm{A}_{400}=$ absorbance at $400 \mathrm{~nm}$. Error bars indicate SD. 
Although STPP and STMP have the same number of phosphate groups $(\mathrm{a}=3)$, turbidity recorded for MC-STPP and MC-STMP mixtures at equivalent salt concentrations were not comparable (Figure 1c,d). The MC-STMP mixture gave a higher $\mathrm{C}^{*}$ in comparison to the MC-STPP mixture, suggesting that not only the number of phosphate groups, but also the structure of salts, play a crucial role in the disintegration of $\mathrm{MC}$. The destabilization mechanism of MC by phosphate salts is proposed to be salt dependent (Mizuno and Lucey, 2005; Kaliappan and Lucey, 2011). Our results indicate that linear phosphate salts can destabilize MC more effectively than those with a ring structure when compared on the basis of an equal number of phosphate groups. Chelation of calcium by phosphate salts could be a potential factor that leads to disintegration of MC. In fact, a difference in calcium binding ratios between disodium phosphate and disodium uridine phosphate (both having a single phosphate group) has been previously reported by de Kort et al. (2011), with the former showing a higher calcium binding capacity.

The MC-salt mixtures made with TSPP, STPP, SHMP, and SPP showed a peak in $\eta_{\text {app }}$ within the experimental salt concentration range (Figure 1b,d,e,f). The salt concentration where the peak $\eta_{\text {app }}$ was observed was considered as the second critical salt concentration $\left(\mathbf{C}^{* *}\right)$. The $\mathrm{C}^{* *}$ values for different phosphate salts are given in Table 1 . In all cases, $\mathrm{C}^{* *}$ was higher than $\mathrm{C}^{*}$. At $\mathrm{C}^{* *}$, turbidity of the MC-salt mixtures reached closer to minimum.

Unlike $\mathrm{C}^{*}, \mathrm{C}^{* *}$ did not show a relationship with the number of phosphate groups present in the salt. The $\mathrm{C}^{* *}$ values recorded for STPP $(\mathrm{a}=3)$ and SHMP $(\mathrm{a}=$ 6 ) were the same irrespective of the difference in their number of phosphate groups. In addition, peak $\eta_{\text {app }}$ values did not show a relationship with the number of phosphate groups present in the salt. The use of TSPP $(\mathrm{a}=2)$ resulted in the highest $\eta_{\text {app }}\left(8 \times 10^{-2} \mathrm{~Pa} \cdot \mathrm{s}\right.$ at $\mathrm{C}^{* *}$; Figure $1 \mathrm{~b}$ ), which was nearly 8 -fold higher than the peak $\eta_{\text {app }}$ values observed for the other salts. The MSP and STMP showed a continued increase in $\eta_{\text {app }}$ (no peak) with increasing salt concentration (Figure 1a,c). The $\mathrm{C}^{*}$ values obtained for these 2 salts were higher compared with the other MC-salt mixtures (Table 1) and the peak viscosities of these mixtures may occur beyond the highest experimented MSP and STMP concentrations $(>100 \mathrm{mM})$.

\section{Effect of Salt Type and Salt Concentration on Flow Behavior}

Apparent viscosity versus shear rate curves derived for $5 \% \mathrm{wt} / \mathrm{vol} \mathrm{MC}$-salt mixtures and the fitting of Equation [2] to the power law region $\left(5-100 \mathrm{~s}^{-1}\right)$ of these curves are presented in Supplemental Figures S3 and S4, respectively (https://doi.org/10.3168/jds.2018 -15746). The $K$ and $n$ values of these mixtures at different salt concentrations are presented in Figure 2. At $\mathrm{C}^{* *}$ of TSPP, a prominent shear thinning behavior was observed in the MC-salt mixture compared with the other TSPP concentrations (Supplemental Figures S3b and S4b; https://doi.org/10.3168/jds.2018-15746). Flow index, $n$, reached a minimum of 0.3 at $\mathrm{C}^{* *}$ of TSPP in comparison to an $n$ of $\sim 0.9$ at other TSPP concentrations (Figure 2b). However, the use of other phosphate salts did not result in a marked deviation in their flow behavior at $\mathrm{C}^{* *}$, and the change of $n$ was generally $\leq 0.1$ within the experimented concentration range. The consistency coefficient, $K$, reached a maximum at $\mathrm{C}^{* *}$ of TSPP, in parallel with the higher $\eta_{\text {app }}$

Table 1. The first critical salt concentration $\left(\mathrm{C}^{*}\right)$ and second critical salt concentration $\left(\mathrm{C}^{* *}\right)$ values obtained for micellar casein (MC) solutions in the presence of different phosphate salts

\begin{tabular}{|c|c|c|c|c|c|}
\hline \multirow[b]{2}{*}{ Salt $^{1}$} & \multirow[b]{2}{*}{$\begin{array}{c}\text { No. of } \mathrm{PO}_{4}^{3-} \\
\text { groups }(\mathrm{a})^{2}\end{array}$} & \multicolumn{2}{|c|}{$5 \% \mathrm{wt} / \mathrm{vol} \mathrm{MC}$} & \multicolumn{2}{|c|}{$9.6 \% \mathrm{wt} / \mathrm{vol} \mathrm{MC}$} \\
\hline & & $\begin{array}{l}\mathrm{C}^{*} \\
(\mathrm{~m} M)\end{array}$ & $\begin{array}{l}\mathrm{C}^{* *} \\
(\mathrm{~m} M)\end{array}$ & $\begin{array}{c}\mathrm{C}^{*} \\
(\mathrm{~m} M)\end{array}$ & $\begin{array}{c}\mathrm{C}^{* *} \\
(\mathrm{~m} M)\end{array}$ \\
\hline MSP & 1 & 34.1 & -3 & -4 & -4 \\
\hline TSPP & 2 & 1.2 & 10.0 & 3.7 & 15.0 \\
\hline STMP & 3 & 21.7 & $-^{3}$ & $-{ }^{4}$ & $-^{4}$ \\
\hline STPP & 3 & 1.0 & 2.5 & 2.0 & 5.0 \\
\hline SHMP & 6 & 0.7 & 2.5 & 1.6 & 5.0 \\
\hline SPP & 17 & 0.2 & 1.0 & 0.7 & 2.5 \\
\hline
\end{tabular}

${ }^{1} \mathrm{MSP}=$ sodium phosphate monobasic; $\mathrm{TSPP}=$ sodium pyrophosphate tetrabasic; $\mathrm{STMP}=$ sodium trimetaphosphate; $\mathrm{STPP}=$ sodium tripolyphosphate; $\mathrm{SHMP}=$ sodium hexametaphosphate; $\mathrm{SPP}=$ sodium polyphosphate.

${ }^{2}$ (a) number of phosphate groups in SPP is an average.

${ }^{3}$ Beyond the experimented range.

${ }^{4}$ Not measured/estimated. 
observed. The ability of TSPP to markedly alter the flow properties of $\mathrm{MC}$ solutions at $\mathrm{C}^{* *}$ suggests that the chemical structure of a salt has a prominent effect on interactions among dissociated MC species, rather than the number of phosphate groups present in a salt.
Effect of MC Concentration on $C^{*}, C^{* *}$, and Flow Behavior

Mixtures prepared with salts TSPP, STPP, SHMP, and SPP were selected for the higher MC concentra-
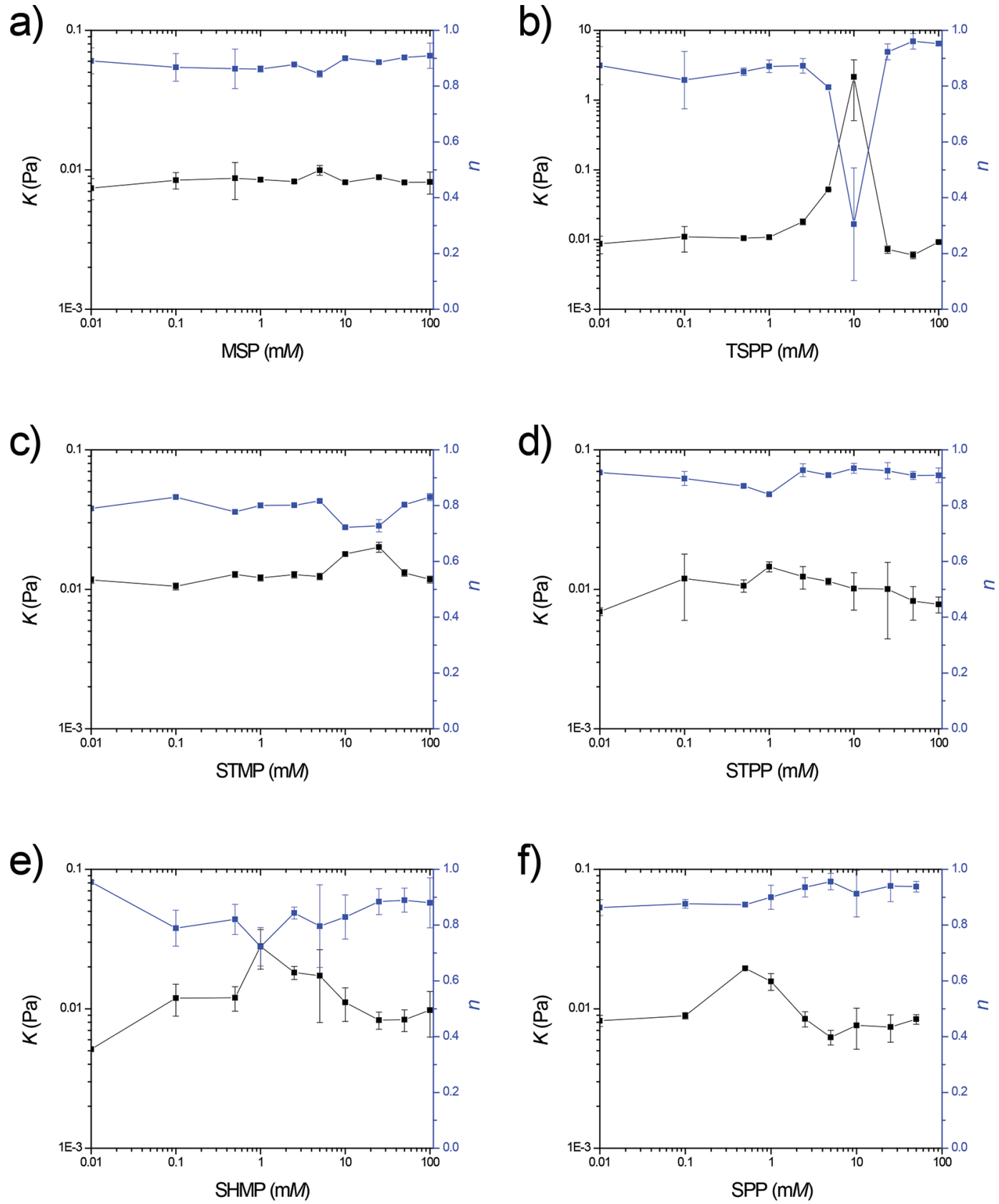

Figure 2. Consistency coefficients ( $K$; black) and flow indices ( $n$; blue) of $5 \% \mathrm{wt} /$ vol micellar casein (MC) solutions with varying concentrations of different phosphate salts at $5^{\circ} \mathrm{C}$. (a) Sodium phosphate monobasic (MSP), (b) sodium pyrophosphate tetrabasic (TSPP), (c) sodium trimetaphosphate (STMP), (d) sodium tripolyphosphate (STPP), (e) sodium hexametaphosphate (SHMP), and (f) sodium polyphosphate (SPP). The MC-salt mixtures were prepared using $10 \mathrm{~m} M$ HEPES buffer (pH 7.0). The $K$ and $n$ values were obtained by fitting Equation [2] with the power law region of viscosity plots (Supplemental Figure S4; https://doi.org/10.3168/jds.2018-15746). Error bars indicate SD. 
tion studies. Increasing the MC concentration of the mixtures to $9.6 \% \mathrm{wt} / \mathrm{vol}$ did not alter the trend observed for turbidity with increasing salt concentration (Figure 3), but it shifted the curve toward a higher salt concentration. $\mathrm{G}^{*}$ was measured for these high MC concentration mixtures, as some of them resulted in gel formation. The salt concentration that resulted in a peak $\mathrm{G}^{*}$ was considered as $\mathrm{C}^{* *}$. The $\mathrm{G}^{*}$ at $9.6 \% \mathrm{wt} /$ vol $\mathrm{MC}$ concentration followed a similar trend to $\eta_{\text {app }}$ at $5 \% \mathrm{wt} / \mathrm{vol} \mathrm{MC}$ concentration, but showed a rightward shift, similar to the turbidity. The shift of the turbidity and $\mathrm{G}^{*}$ curves resulted in higher $\mathrm{C}^{*}$ and $\mathrm{C}^{* *}$ values for $9.6 \% \mathrm{wt} / \mathrm{vol} \mathrm{MC}$ in comparison to those obtained at $5 \% \mathrm{wt} / \mathrm{vol} \mathrm{MC}$ (Table 1). The increase in critical concentrations was attributed to the increased MC to salt ratio, thus requiring higher salt concentrations to exert the same effects on more MC. In fact, the increments observed for $\mathrm{C}^{*}$ and $\mathrm{C}^{* *}$ were in the order of the increase of $\mathrm{MC}$ concentration (Table 1).

In comparison to STPP and SPP, higher $\mathrm{G}^{*}$ values were observed for both SHMP and TSPP at their $\mathrm{C}^{* *}$ (Figure 3a,c). The TSPP and SHMP had tan $\delta$ values
$<1$ and $\mathrm{G}^{\prime}>1 \mathrm{~Pa}$ (Supplemental Figure S5; https://doi .org/10.3168/jds.2018-15746) suggesting gel formation at their $\mathrm{C}^{* *}$ (Winter and Chambon, 1986; Kavanagh et al., 2000). It has been previously proposed that these salts lead to gel formation by cross-linking of dispersed casein proteins (Mizuno and Lucey, 2007; de Kort et al., 2011). Moreover, the markedly higher $\mathrm{G}^{\prime \prime}$ observed in the presence of TSPP $(\mathrm{a}=2)$ compared with that of SHMP $(\mathrm{a}=6)$ and the magnitude of difference between $\mathrm{G}^{\prime \prime}$ and $\mathrm{G}^{\prime}$ values (Supplemental Figure S5; https://doi .org/10.3168/jds.2018-15746) suggests that the number of phosphate groups alone does not determine gel strength.

Viscosity curves derived for the $9.6 \% \mathrm{wt} / \mathrm{vol} \mathrm{MC}$ salt mixtures and the fitting of Equation [2] to their power law region are shown in Supplemental Figures S6 and S7, respectively (https://doi.org/10.3168/jds.2018 -15746). The $K$ and $n$ values obtained for these MC-salt mixtures are plotted in Figure 4. At 9.6\% wt/vol MC concentration, all the selected MC-salt mixtures resulted in a pronounced shear thinning behavior at $\mathrm{C}^{* *}$ (Figure 4), in contrast to the lower MC concentration
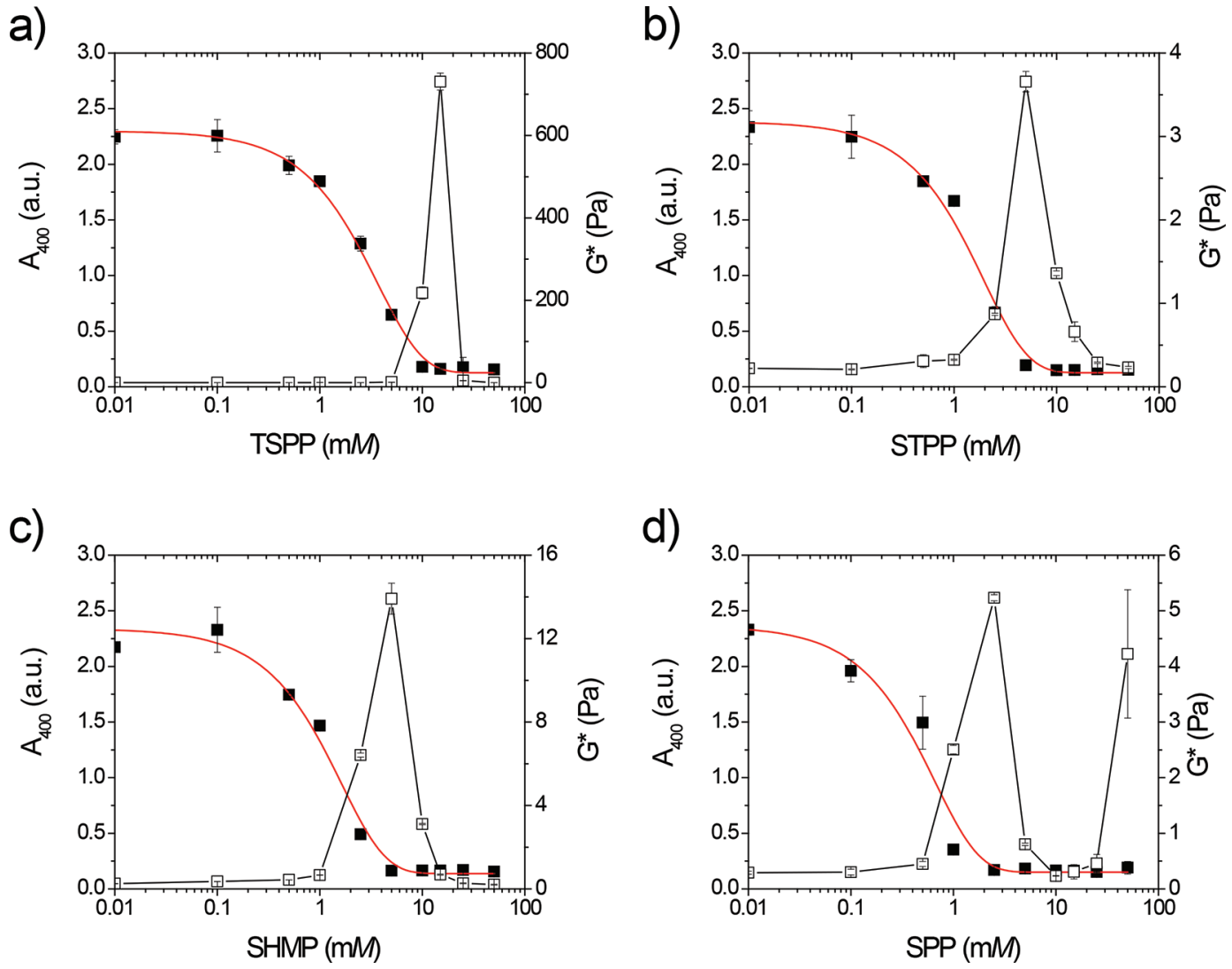

Figure 3. Turbidity and complex modulus $\left(\mathrm{G}^{*}\right)$ of $9.6 \% \mathrm{wt} / \mathrm{vol}$ micellar casein $(\mathrm{MC})$ solutions with varying concentrations of different phosphate salts at $5^{\circ} \mathrm{C}$. (a) Sodium pyrophosphate tetrabasic (TSPP), (b) sodium tripolyphosphate (STPP), (c) sodium hexametaphosphate (SHMP), and (d) sodium polyphosphate (SPP). The MC-salt mixtures were prepared using $10 \mathrm{~m} M$ HEPES buffer (pH 7.0). The red curve shows fitting of an exponential model to the turbidity data using Equation [1]. $\mathrm{A}_{400}=$ absorbance at $400 \mathrm{~nm}$. Error bars indicate SD. 
a)
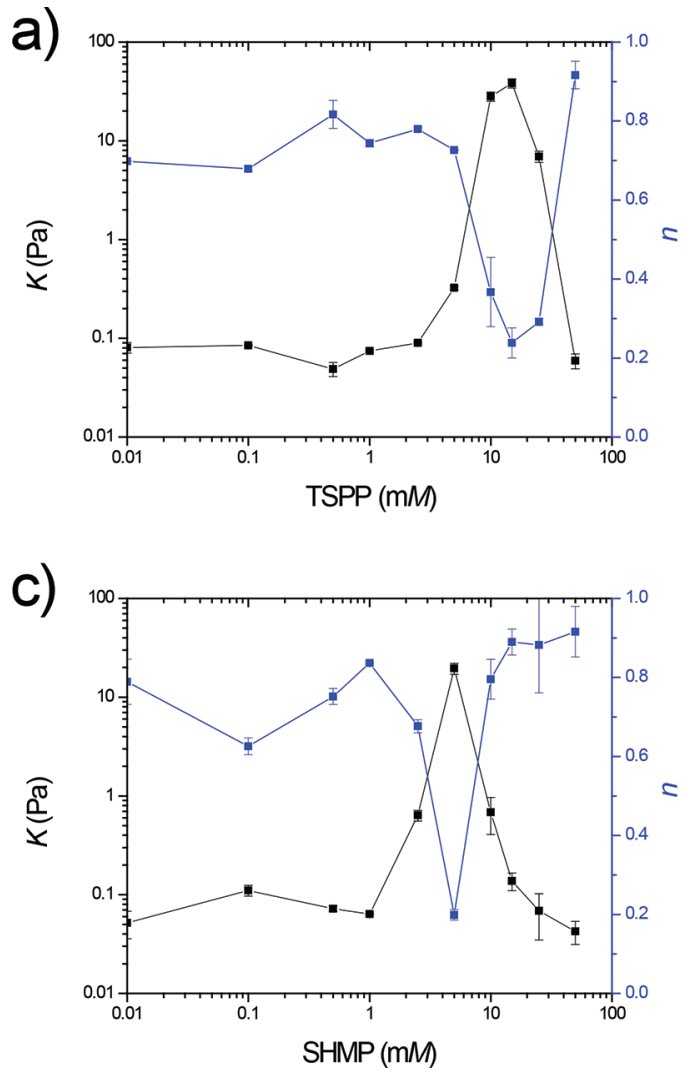

b)

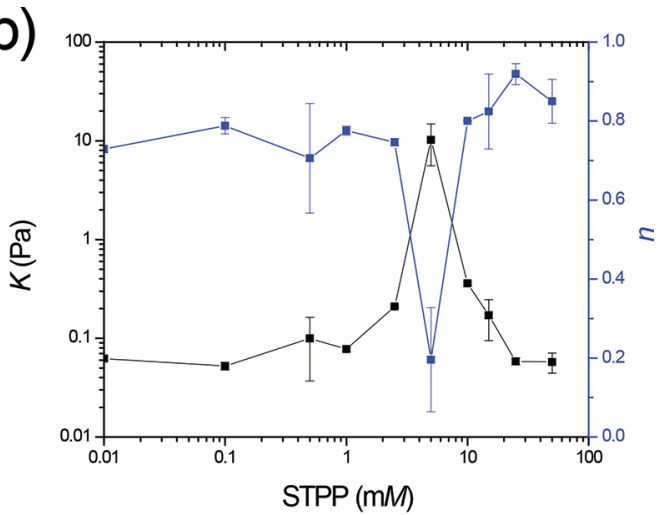

d)

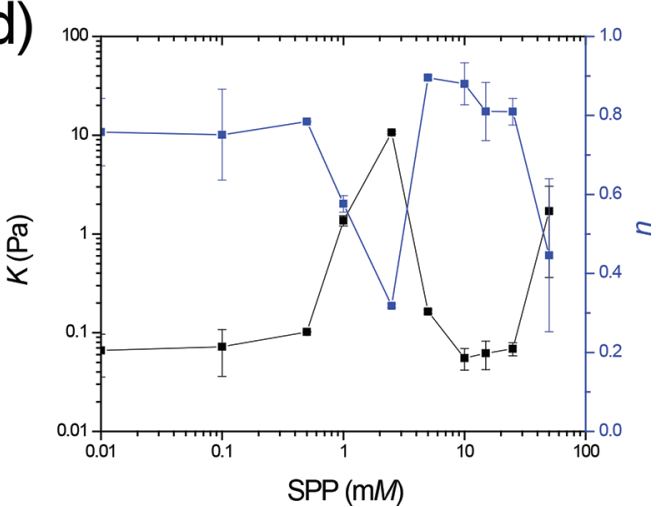

Figure 4. Consistency coefficients ( $K$; black) and flow indices ( $n$; blue) of $9.6 \% \mathrm{wt} /$ vol micellar casein (MC) solutions with varying concentrations of different phosphate salts at $5^{\circ} \mathrm{C}$. (a) Sodium pyrophosphate tetrabasic (TSPP), (b) sodium tripolyphosphate (STPP), (c) sodium hexametaphosphate (SHMP), and (d) sodium polyphosphate (SPP). The MC-salt mixtures were prepared using $10 \mathrm{mM}$ HEPES buffer (pH 7.0). The $K$ and $n$ values were obtained by fitting Equation [2] with the power law region of viscosity plots (Supplemental Figure S7; https://doi.org/ 10.3168/jds.2018-15746). Error bars indicate SD.

(5\% wt/vol), where only TSPP showed a shear thinning behavior at $\mathrm{C}^{* *}$. The $n$ values for TSPP, STPP, $\mathrm{SHMP}$, and $\mathrm{SPP}$ at $\mathrm{C}^{* *}$ were estimated to be $\sim 0.25$, $0.2,0.2$, and 0.3 , respectively, whereas $n$ generally deviated between 0.7 and 0.9 at the other salt concentrations (Figure 4). However, SPP again showed a shear thinning behavior at $50 \mathrm{~m} M\left(>\mathrm{C}^{* *}\right)$ with an $n$ of 0.45 , a trend that we did not observe with the other salts.

\section{Effect of Salt Concentration on Morphology of MC}

To observe the structural changes that occur in MC with increasing phosphate salt concentration, cryo-EM images were obtained for the $5 \% \mathrm{wt} / \mathrm{vol}$ MC-SHMP mixtures having different SHMP concentrations. In contrary to the observed reduction in turbidity, cryo-EM images showed the existence of micelles/ micellar-like structures in MC-SHMP mixtures up to $5 \mathrm{~m} M$ SHMP concentration (Supplemental Figure S8; https://doi.org/10.3168/jds.2018-15746). The size of the micelles present in the mixtures varied with salt concentration. Micelle size increased (in comparison to their size in the absence of salt) when the SHMP concentration reached $1 \mathrm{~m} M$ (Figure S8e,f; https:// doi.org/10.3168/jds.2018-15746). However, micelle size gradually decreased (from $\sim 275-300 \mathrm{~nm}$ to $\sim 80-150$ $\mathrm{nm}$ ) when the SHMP concentration was increased from 1 to $5 \mathrm{mM}$ (Figure S8e-j; https://doi.org/10.3168/jds .2018-15746). No micelle-like structures were observed at $100 \mathrm{~m} M$ SHMP (images not shown), suggesting that all the micelles eventually disintegrated into casein monomers or soluble casein aggregates. However, given the fact that MC-SHMP mixtures appeared nearly transparent at SHMP concentrations $\geq 2.5 \mathrm{~m} M$, it is questionable how fairly the cryo-EM images (i.e., the observed micellar-like structures) represent the true composition of MC-SHMP mixtures. A possible explanation for the observation of micellar-like structures at SHMP concentrations $\geq 2.5 \mathrm{~m} M$ could be that we are observing clusters formed of individual casein species present in the mixtures. Moreover, the resolution of the cryo-EM images was not sufficient to identify fine structural differences among the micelles/micellarlike structures observed at different salt concentrations 
(e.g., CCP nanocluster density). Hence, no conclusive remarks were drawn based on cryo-EM results.

We suggest that at concentrations below $\mathrm{C}^{*}$, interactions between salts and CCP nanoclusters are limited, thus the structure of micelles remains closer to the native/original state. At $\mathrm{C}^{*}$ (and $<\mathrm{C}^{* *}$ ), salts start to deplete $\mathrm{CCP}$ nanoclusters (by chelation of calcium) from MC. Depletion of CCP nanoclusters could also lead to a release of a fraction of caseins from $\mathrm{MC}$ to the serum. The structural changes occurring in MC with the increase of salt concentration are believed to be responsible for the observed reduction in turbidity of MC-salt mixtures (Figure 1). The concomitant increase in viscosity of the mixtures is attributed to the increase of serum protein concentration and their interactions.

At $\mathrm{C}^{* *}$, turbidity of the mixtures is at (or near to) minimum (Figure 1), suggesting that most of the MC present in the mixtures have been completely disintegrated into serum caseins. Further loss of CCP nanoclusters and weakening of casein-casein interactions within the micelles with the increase of salt concentration may lead to collapse of the organized micelle structure, forming serum casein species. Increase of serum casein content and interactions among these species in the presence of polyphosphates could lead to formation of a network (Mizuno and Lucey, 2007; de Kort et al., 2011), increasing the viscosity of the MC-salt mixtures (Figure 1). Whey proteins present in the mixtures (Supplemental Figure S1; https://doi.org/10.3168/jds .2018-15746) could also take part in these interactions to a minor extent.

Among the phosphate salts, TSPP showed the highest $\eta_{\text {app }}$ at $\mathrm{C}^{* *}$, which was 8-fold higher than the peak $\eta_{\text {app }}$ reported for other salts (Figure 1). Thus, in the presence of TSPP (at $\mathrm{C}^{* *}$ ), a more cohesive network could have been formed by the serum caseins compared with the other phosphate salts. Transmission electron microscopy images obtained for the $5 \% \mathrm{wt} / \mathrm{vol}$ MC-TSPP at $\mathrm{C}^{* *}$ showed a tightly woven network in comparison to that observed for 5\% wt/vol MC-SHMP at $\mathrm{C}^{* *}$ (Supplemental Figure S9; https://doi.org/10 $.3168 /$ jds.2018-15746). However, it should be noted that the transmission electron microscopy images do not provide conclusive evidence because drying of the samples during grid preparation and staining could lead to artifacts.

When the salt concentration was increased beyond $\mathrm{C}^{* *}$, a sudden drop in viscosity was observed (Figure 1), suggesting that interactions among serum protein species are highly dependent on salt concentration/ ionic strength. Masking of charges by salt ions could have possibly weakened the electrostatic interactions among the serum caseins, thus reducing the viscosity/ gel strength of the mixtures.

\section{CONCLUSIONS}

Phosphate salts caused an exponential decay in turbidity of MC-salt mixtures at $\mathrm{pH} 7.0$ with the increase of salt concentration. The inflection point of the turbidity curve was identified as the $\mathrm{C}^{*}$ that initiates dissociation of MC. Salts containing a higher number of phosphate groups had a lower $\mathrm{C}^{*}$ in general. Apparent viscosity of MC solutions reached a peak value with further increase of salt concentration, and the corresponding salt concentration was identified as $\mathrm{C}^{* *}$. At $\mathrm{C}^{* *}$, interactions among protein species present in the mixtures are believed to be at an optimum state. Both $\mathrm{C}^{*}$ and $\mathrm{C}^{* *}$ were found to be dependent on the $\mathrm{MC}$ concentration. Moreover, at higher MC concentration, a prominent shear thinning behavior was observed at $\mathrm{C}^{* *}$. The work presented herein supports an understanding of the concentration effect of different phosphate salts on MC, which is applicable for structuring dairy products.

\section{ACKNOWLEDGMENTS}

This research was mainly funded by the National Dairy Council (Chicago, IL) through the project "Prototype to study the effect of ionic environments on casein micelle integrity." The work was also partially supported by the USDA National Institute of Food and Agriculture Federal Appropriations under the project PEN04565 and accession number 1002916. The authors appreciate Grace Lewis (Department of Food Science, Pennsylvania State University) for her assistance with characterization of $\mathrm{MC}$ powder.

\section{REFERENCES}

Ambrose Griffin, M. C., and W. G. Griffin. 1985. A simple turbidimetric method for the determination of the refractive index of large colloidal particles applied to casein micelles. J. Colloid Interface Sci. 104:409-415.

Broyard, C., and F. Gaucheron. 2015. Modifications of structures and functions of caseins: A scientific and technological challenge. Dairy Sci. Technol. 95:831-862.

Caron, A., D. St-Gelais, and Y. Pouliot. 1997. Coagulation of milk enriched with ultrafiltered or diafiltered microfiltered milk retentate powders. Int. Dairy J. 7:445-451.

Carr, A., and M. Golding. 2016. Functional milk proteins production and utilization: Casein-based Ingredients. Pages 35-66 in Advanced Dairy Chemistry: Volume 1B: Proteins: Applied Aspects. P. L. H. McSweeney and J. A. O'Mahony, ed. Springer New York, New York, NY.

Chavhan, G. B., S. K. Kanawjia, Y. Khetra, and R. Puri. 2015. Effect of potassium-based emulsifying salts on sensory, textural, and functional attributes of low-sodium processed Mozzarella cheese. Dairy Sci. Technol. 95:265-278.

Creamer, L. K., J. E. Plowman, M. J. Liddell, M. H. Smith, and J. P. Hill. 1998. Micelle stability: $\kappa$-casein structure and function. J. Dairy Sci. 81:3004-3012. 
Culler, M. D., Y. Saricay, and F. M. Harte. 2017. The effect of emulsifying salts on the turbidity of a diluted milk system with varying pH and protein concentration. J. Dairy Sci. 100:4241-4252.

Dalgleish, D. G. 2011. On the structural models of bovine casein micelles - Review and possible improvements. Soft Matter 7:22652272 .

de Kort, E., M. Minor, T. Snoeren, T. van Hooijdonk, and E. van der Linden. 2011. Effect of calcium chelators on physical changes in casein micelles in concentrated micellar casein solutions. Int. Dairy J. 21:907-913.

de Kruif, C. G., T. Huppertz, V. S. Urban, and A. V. Petukhov. 2012. Casein micelles and their internal structure. Adv. Colloid Interface Sci. 171-172:36-52.

Holt, C., J. A. Carver, H. Ecroyd, and D. C. Thorn. 2013. Invited review: Caseins and the casein micelle: their biological functions, structures, and behavior in foods. J. Dairy Sci. 96:6127-6146.

Horne, D. S. 1998. Casein interactions: Casting light on the black boxes, the structure in dairy products. Int. Dairy J. 8:171-177.

Hougaard, A. B., A. G. Sijbrandij, C. Varming, Y. Ardö, and R. Ipsen. 2015. Emulsifying salt increase stability of cheese emulsions during holding. Lebensm. Wiss. Technol. 62:362-365.

Kaliappan, S., and J. A. Lucey. 2011. Influence of mixtures of calcium-chelating salts on the physicochemical properties of casein micelles. J. Dairy Sci. 94:4255-4263.

Kapoor, R., and L. E. Metzger. 2008. Process cheese: Scientific and technological aspects-A review. Compr. Rev. Food Sci. Food Saf. 7:194-214.

Kavanagh, G. M., A. H. Clark, W. S. Gosal, and S. B. Ross-Murphy. 2000. Heat-induced gelation of $\beta$-lactoglobulin/ $\alpha$-lactalbumin blends at pH 3 and pH 7. Macromolecules 33:7029-7037.

Kawasaki, K., and K. M. Weiss. 2003. Mineralized tissue and vertebrate evolution: The secretory calcium-binding phosphoprotein gene cluster. Proc. Natl. Acad. Sci. USA 100:4060-4065.

Kumosinski, T. F., and H. M. Farrell. 1991. Calcium-induced associations of the caseins: Thermodynamic linkage of calcium binding to colloidal stability of casein micelles. J. Protein Chem. 10:3-16.
Laemmli, U. K. 1970. Cleavage of structural proteins during the assembly of the head of bacteriophage T4. Nature 227:680.

Lucey, J. A., A. Maurer-Rothmann, and S. Kaliappan. 2011. Functionality of ingredients: Emulsifying salts. Pages 110-132 in Processed Cheese and Analogues. A. Y. Tamime, ed. Wiley-Blackwell, West Sussex, UK.

Mizuno, R., and J. A. Lucey. 2005. Effects of emulsifying salts on the turbidity and calcium-phosphate-protein interactions in casein micelles. J. Dairy Sci. 88:3070-3078.

Mizuno, R., and J. A. Lucey. 2007. Properties of milk protein gels formed by phosphates. J. Dairy Sci. 90:4524-4531.

Panouillé, M., L. Benyahia, D. Durand, and T. Nicolai. 2005. Dynamic mechanical properties of suspensions of micellar casein particles. J. Colloid Interface Sci. 287:468-475.

Pitkowski, A., T. Nicolai, and D. Durand. 2008. Scattering and turbidity study of the dissociation of casein by calcium chelation. Biomacromolecules 9:369-375.

Schneider, C. A., W. S. Rasband, and K. W. Eliceiri. 2012. NIH Image to ImageJ: 25 years of image analysis. Nat. Methods 9:671-675.

Schokker, E. P. J. S. Church, J. P. Mata, E. P. Gilbert, A. Puvanenthiran, and P. Udabage. 2011. Reconstitution properties of micellar casein powder: Effects of composition and storage. Int. Dairy J. 21:877-886.

St-Gelais, D., D. Roy, and P. Audet. 1998. Manufacture and composition of low fat Cheddar cheese from milk enriched with different protein concentrate powders. Food Res. Int. 31:137-145.

Trejo, R., T. Dokland, J. Jurat-Fuentes, and F. Harte. 2011. Cryotransmission electron tomography of native casein micelles from bovine milk. J. Dairy Sci. 94:5770-5775.

Winter, H. H., and F. Chambon. 1986. Analysis of linear viscoelasticity of a crosslinking polymer at the gel point. J. Rheol. (N.Y.N.Y.) $30: 367-382$. 